\title{
REFUGIADO: ASPECTO LEGAL E SOCIAL
}

\author{
Juliana Fernandes Mingutti* \\ Bárbara Mourão SachetT**
}

\section{RESUMO}

O presente trabalho tem por objetivo, identificar a relação dos refugiados com a Lei brasileira e o enfrentamento na sociedade diante de um cenário adverso. Buscou-se por meio de uma pesquisa exploratória, entender como o refugiado tem os serviços básicos acolhidos e como é a relação com a sociedade. Contudo, explorar o conceito de direitos humanos e sua trajetória é fator essencial para o entendimento da garantia e proteção do refugiado, assim como, delimitar quem são os refugiados e como a lei local aborda a sua proteção. A marginalização das minorias abre caminhos à discriminação, e com a pessoa na figura do refugiado não seria diferente, e tratar desta polêmica, desmistifica todo o estigma que paira sobre a pessoa perseguida que vem em busca de melhores condições de vida. Tratou-se, todavia, por análises bibliográficas, esclarecer esta discriminação e o distanciamento do refugiado perante a sociedade, sendo o desconhecimento do que seja refugiado a sua condição para esta vulnerabilidade social. Por fim, a pesquisa nos trouxe um panorama otimista em relação ao acolhimento dos serviços básicos, num comparativo com pontos negativos no que importa a integração do refugiado na sociedade, com lacunas para melhorias, como o entendimento de quem são os refugiados, melhor aceitação dos documentos expedidos pelas autoridades brasileiras, entre outros assuntos identificados ao longo do trabalho.

Palavras-chave: Direitos Humanos. ONU. ACNUR. Refugiados.

\section{REFUGEE: LEGAL AND SOCIAL ASPECT}

\section{ABSTRACT}

This paper aims to identify the relationship of refugees with Brazilian law and confrontation in society in the face of an adverse scenario. An exploratory research was sought to understand how the refugee has the basic services received and how is the relationship with society. However, exploring the concept of human rights and its trajectory are essential factors in understanding refugee security and protection, as well as defining who refugees are and how local law addresses their protection. The marginalization of minorities opens the way to discrimination, and with the person in the refugee figure would be no different, and addressing this controversy demystifies all the stigma

* Advogada, estudante egressa do Curso de Direito da Universidade Metodista de São Paulo em dezembro de 2019.Endereço eletrônico: juliana.mingutti@hotmail.com.

** Mestre em Direito pela Universidade Estadual Paulista Júlio de Mesquita Filho - UNESP. Doutoranda em Direito pela Universidade de São Paulo (USP). Advogada. Professora Universitária. Endereço eletrônico: barbara.sachett@metodista.br. 
that hangs under the persecuted person who comes in search of better living conditions and who cannot suffer for it. once again. However, bibliographic analyzes were intended to clarify this discrimination and the distancing of the refugee from society, and the lack of knowledge of what is a refugee is his condition for this social vulnerability. Finally, the research provided us with an optimistic outlook on the reception of basic services, but in a comparison, with negative points regarding the integration of the refugee in society, with gaps for improvement, such as understanding who the refugees are, better acceptance of documents issued by the Brazilian authorities, among other matters, identified throughout the work.

Keywords: Human Rights. ONU. ACNUR. Refugees.

\section{INTRODUÇÃO}

O tema deste estudo merece reflexão, pois apesar de não ser uma questão atual, o refúgio tem sido alvo de grande visibilidade, principalmente depois das circunstâncias de guerra na Síria, e com migração crescente em vários lugares da Europa, impondo a abertura de grandes campos para acolhimento desses migrantes.

$\mathrm{O}$ ingresso desses migrantes na cidade de São Paulo ainda é tímido, se comparado com a larga escala europeia, mas não menos importante, considerando a instabilidade da nossa economia e situação política.

Por isso, o objetivo deste estudo é identificar as condições em que os refugiados são tratados de acordo com o previsto na legislação local e o que sua figura reflete na sociedade, como o relacionamento dos refugiados com os serviços básicos de emissão de documentos, até a sua rejeição de modo discriminatório por parte da sociedade.

Deste modo, o texto a seguir está organizado em 3 seções. A primeira delas, Direitos Humanos e sua universalização, concentra-se em abordar a importância dos direitos humanos e sua atuação no mundo, enfatizando a sua criação no pós-guerra, assim como, sua disseminação por meio da Declaração Universal dos Direitos Humanos e a regionalização para uma melhor compreensão e aproximação com o direito local, na garantia da proteção da pessoa humana.

Na seguinte seção, Refúgio, sua significância e transcendência, pondera-se o conceito de refugiados, tal qual, a atuação da ACNUR (Alto Comissariado das Nações Unidas para Refugiados), juntamente com o CONARE (Comitê Nacional para os Refugiados), na promoção de assistência e proteção dos refugiados, enfatizando as Leis 9.474/1997 e 13.445/2017, com números atuais e cada vez mais crescentes de solicitações de refúgio.

Finalizando, a terceira seção, nomeada de Análise qualitativa, cotejando os aspectos jurídicos e sociais a partir do olhar do refugiado, nos apresenta uma abordagem por meio de uma pesquisa qualitativa e análise sociológica, trazendo narrativas importantes na consideração de dois refugiados, que apontam aspectos favoráveis na sua garantia de direitos e desfavoráveis, no aspecto social, como a discriminação por falta de entendimento da sociedade do que seja um refugiado. 


\section{DIREITOS HUMANOS E SUA UNIVERSALIZAÇÃO}

Para o dicionário Houaiss (2019, p. 1), a explicação de direitos humanos consiste em:

reunião dos direitos (proteções legais) que, garantidos pela lei, são universais e inerentes a qualquer ser humano, independente de sua raça, sexo, nacionalidade, etnia, religião, convicção política ou qualquer outra condição de ordem social, nacional ou própria do nascimento: o direito à vida, à educação, ao trabalho e à liberdade são direitos humanos.

Segundo a Organização das Nações Unidas, o conceito é bem parecido, sendo "os direitos inerentes a todos os seres humanos, independentemente de raça, sexo, nacionalidade, etnia, idioma, religião ou qualquer outra condição". (ONU, 2019, p. 2). Contudo a definição é muito mais ampla diante da condição prática que a sociedade esbarra: a falta de entendimento legal e social do próprio conceito.

Os direitos humanos da atualidade, se estabeleceram diante do cenário internacional degradante, após especificamente, a Segunda Guerra Mundial, em virtude das violações e atrocidades vivenciadas por todos os países envolvidos com o conflito, despertando assim, uma consciência universal de garantia e proteção ao direito do ser humano, se desenvolvendo e se mantendo através da evolução da história (PIOVESAN, 2011).

De acordo com Piovesan (2011, p. 37), “a barbárie do totalitarismo significou a ruptura do paradigma dos direitos humanos, por meio da negação do valor da pessoa humana como valor-fonte do Direito".

Para melhor compreensão, Mazzuoli (2015) destaca que a evolução gradual da história é pautada em gerações de direito, como direitos da liberdade, igualdade e fraternidade. E para continuidade da luta pelo direito, não se pode considerar tais gerações como passagens divisíveis entre gerações, e sim, como uma progressão e continuidade da luta pelo direito, resultante na proteção da pessoa humana.

Neste sentido, Bobbio (2004, p. 26) reforça a ideia de que as gerações de direitos devem se complementar através da história:

[...] os direitos não nascem todos de uma vez. Nascem quando devem ou podem nascer. Nascem quando o aumento do poder do homem sobre o homem - que acompanha inevitavelmente o progresso técnico, isto é, o progresso da capacidade do homem de dominar a natureza e os outros homens - ou cria novas ameaças à liberdade do indivíduo, ou permite novos remédios para as suas indigências: ameaças que são enfrentadas através de demandas de limitações do poder; remédios que são providenciados através da exigência de que o mesmo poder intervenha de modo protetor.

E sob esta perspectiva de proteção aos direitos humanos, foi traçado um sistema normativo de amplitude internacional, enfraquecendo a soberania nacional de cada Estado, impondo limites e enaltecendo as garantias da dignidade da pessoa humana. Vale ressaltar que cada vez mais, há um alinhamento entre a Constituição 
de cada Estado com o Direito Internacional, visando desta forma repelir toda e qualquer ação que seja considerada violação aos direitos humanos. (PIOVESAN, 2011).

A Declaração Universal dos Direitos Humanos, datada de 1948, deu início a uma série de garantias positivadas em um documento, criando-se um vínculo entre direito internacional e o direito interno, na direção de resguardar um limite mínimo de garantias. (PIOVESAN, 2004).

A Carta da ONU passa a considerar vários direitos, até então caracterizados como restritos e obscuros, para uma gama de garantias previstas para todos, destacando características em sua amplitude, atribuições mínimas para a progressão do ser humano no que tange sua natureza física, moral e intelectual e na sua universalidade, invocando a acessibilidade a todo tipo de pessoa, eliminando o caráter racial (raça pura ariana), que o nazismo trazia. (PIOVESAN, 2004).

Desta forma, Piovesan (2004, p. 146) conceitua:

a Declaração de 1948 estabelece duas categorias de direitos: os direitos civis e políticos e os direitos econômicos, sociais e culturais. Combina, assim, o discurso liberal e o discurso social da cidadania, conjugando o valor da liberdade ao valor da igualdade.

Para além da Declaração Universal dos Direitos Humanos, enquadrada no sistema normativo global, devemos considerar também o que o direito internacional trata como sistema regional de direitos humanos, que se divide em sistema europeu, americano e africano.

Os sistemas regionais são criados de acordo e em simetria com a Declaração Universal Direitos Humanos. Descreve-se como uma complementação das diretrizes e princípios da Carta da ONU. A regionalidade simplifica a contextualização de valores atinentes de cada região (história, cultura, língua, costumes), traduzindo com maior proximidade a relevância no melhoramento da proteção e garantia dos direitos humanos. (PIOVESAN, 2011).

O sistema europeu, foi o pioneiro e mais consolidado dentro desta divisão global de direitos humanos, enfatizando a sua importância pela fragilidade do momento de pós-guerra que foi criado, e pela sólida base fixadora de um mínimo de amparo para a garantia da dignidade da pessoa humana. O modelo europeu, tem sua instrumentalização realizada pela Convenção Europeia de Direitos Humanos de 1950 e é composta por uma Corte, na qual todos os indivíduos que estão sob a jurisdição dos Estados-membros têm acesso direto e podem invocar ocorrências contra o próprio Estado. (PIOVESAN, 2011).

Embora o sistema europeu tenha uma maior expressão em um âmbito geral, nos limitaremos ao sistema americano, por sua territorialidade.

O sistema regional interamericano de proteção dos direitos humanos tem a sua história traçada na desigualdade social e nos resquícios de regimes ditatoriais, importando, desta forma, em maior violação dos direitos humanos e desobediência nos preceitos da dignidade da pessoa humana. (PIOVESAN, 2011).

Confirmando esta situação, Piovesan (2011, p. 123-124) relata: 
Ao longo dos regimes ditatoriais que assolaram os Estados da região, os mais básicos direitos e liberdades foram violados, sob as marcas das execuções sumárias; dos desaparecimentos forçados; das torturas sistemáticas; das prisões ilegais e arbitrárias; das perseguições político-ideológicas; e da abolição das liberdades de expressão, reunião e associação.

O sistema tem a sua diretriz baseada na Convenção Americana de Direitos Humanos ${ }^{1}$, com admissão reservada somente aos membros da Organização dos Estados Americanos. Consiste, inicialmente, em direitos civis e políticos, sem especificação sobre direito social, cultural e econômico (que foram introduzidos mais tarde por meio do Protocolo de San Salvador ${ }^{2}$ ), cabendo a cada Estado a realização na forma legal interna. A despeito do alcance da democracia, a situação que cabe a cada estado acaba sendo a maior causadora do abismo social, em virtude da falta de desenvolvimento, emanada do direto social, cultural e político - situações contraditórias que resvalam na violação dos direitos humanos e garantia da dignidade da pessoa humana, porém cada Estado tem o direito-dever de arcar com as suas responsabilidades. (PIOVESAN, 2011).

A Convenção Americana utiliza-se de dois mecanismos, que trabalham para o cumprimento do estabelecido na diretriz, entre eles, a Comissão Interamericana de Direitos Humanos e a Corte Interamericana de Direitos Humanos.

A Comissão Interamericana de Direitos Humanos é composta por sete membros eleitos pela Assembleia Geral, por um período de quatro anos, permitido uma única reeleição. Tem legitimidade em participar como membro qualquer nacional integrante do Estado-parte da Organização dos Estados Americanos, e devem ter reconhecimento e sabedoria no que se refere a direitos humanos. (RAMOS, 2017).

A Comissão tem por principal objetivo, a promoção e propagação dos direitos humanos e sua proteção e, além disto, acata outras tarefas, como: preparação de estudos, submissão de relatórios, viabilização e proximidade entre governo e grupos sociais, que tenham o seu direito violado, interferência em pequenos conflitos com intenção saneadora dos atos de violação. Enfim, tem natureza consultiva e de ação, servindo também como principal elo entre o indivíduo comum e o alcance da Corte Interamericana, no tocante à comunicação de violação de direitos humanos. (PIOVESAN, 2004).

Muito embora, o indivíduo comum - ou grupos de indivíduos - tenha a disponibilidade de reclamação à Comissão, esta primeiramente tratará o assunto diante do direito interno para posterior aceitação, submetendo, desta forma, a um juízo de admissibilidade da reclamação, perante ao direito internacional. Significa que as violações aos direitos humanos serão consideradas no âmbito Comissão e Estado-membro, com investigação e recomendação, obedecendo os procedimen-

1 Pacto de San José, convenção assinada em San José, Costa Rica, em 1969, e vigorou a partir de 1978.

2 Protocolo de San Salvador, texto adicional à Convenção, referente a direitos sociais, econômicos e culturais com entrada em vigor em novembro de 1999. 
tos e requisitos da Convenção, para, depois sim, caso o assunto não seja resolvido internamente, seja remetido à Corte Interamericana de Direitos Humanos. (RAMOS, 2017).

Outra forma de peticionamento contra violações de direitos humanos é do Estado-membro contra outro Estado-membro (cláusula facultativa), que seguirá as mesmas orientações de esgotamento dos recursos internos - porém, nesta condição ressaltamos um ponto de observação importante, pois não basta os Estados-membros serem signatários da Convenção. Para que a Comissão possa atuar, ambos os Estados devem declarar expressamente que a mesma, pode examinar a reclamação. A Comissão também pode agir, sem provocação de ninguém, em casos graves e urgentes de violação de direitos humanos, que possam causar danos irreparáveis à pessoa, submetendo o caso diretamente à Corte. (PIOVESAN, 2004).

O outro mecanismo de controle e implantação dos direitos humanos, referenciado na Convenção Americana, é a Corte Internacional de Direitos Humanos.

Trata-se de órgão jurisdicional consultivo e contencioso, composto por sete juízes, eleitos em Assembleia Geral da Organizações dos Estados Americanos, por um mandato de seis anos, com reeleição única. Os Estados-membros podem fazer parte da Convenção Americana dos Direitos Humanos, e não estarem submetidos à jurisdição da Corte Interamericana dos Direitos Humanos, sendo obrigatória declaração específica para tal reconhecimento. (RAMOS, 2017).

As principais demandas da Corte são de natureza consultiva, em que a Comissão ou qualquer outro membro da OEA pode pedir perante a Corte informação em forma de parecer sobre interpretações e divergências entre direito interno e a Convenção; de outro modo, temos o aspecto contencioso da Corte, que atua diretamente na denúncia e na violação do fato. Todas as decisões têm caráter vinculante e o Estado deve cumprir com a obrigação de restabelecimento do direito violado, com indenização às vítimas ou familiares, reorganizar em seu aparato interno, medidas protetivas em simetria com a Convenção. (PIOVESAN, 2004).

Ressalta-se que a legitimidade pera a busca do direito violado no sistema americano é diferente do que é aplicável na Comissão Europeia dos Direitos Humanos, que aceita o indivíduo como legítimo para buscar os seus direitos diretamente com a Corte. No sistema americano, este alcance e legitimidade é reservado a Comissão ou Estamos-membros, restringindo a atuação direta do indivíduo. A denúncia será submetida a Comissão ou Estados-membros, e estes, por sua vez, admitindo-a, encaminhará à Corte. (RAMOS, 2017).

Neste contexto, Trindade (2013, p. 29) reforça a evolução e entendimento geral sobre a atuação das Cortes diante dos direitos:

As Cortes Europeias e Interamericana têm desenvolvido, ao longo dos anos, uma vasta jurisprudência, particularmente no plano do direito substantivo, em relação aos direitos protetivos por ambas a Convenções regionais de direitos humanos. A Corte Europeia conta com uma ampla jurisprudência atinente, e.g., ao direito à proteção da liberdade 
e segurança da pessoa (artigo 5 da Convenção Europeia), e ao direito às garantias do devido processo legal (artigo 6). Por sua vez, a Corte Interamericana possui uma jurisprudência significativa sobre o direito fundamental à vida. (ARTIGO 4. Convenção Americana) [...].

Pelo exposto, salienta-se a importância na regionalização dos sistemas normativos, refletidos nas Convenções, seus desdobramentos, as Comissões e as Cortes para maior influência universal e proximidade na perpetuação, assim como para a garantia dos direitos humanos, e toda impugnação ao abuso dos direitos.

\section{REFÚGIO, SUA SIGNIFICÂNCIA E TRANSCEDÊNCIA}

O fenômeno migratório não é atual, teve início entre as duas grandes guerras, porém com maior relevância na Segunda Guerra Mundial, obrigando uma grande massa de pessoas a migrarem para outros lugares, por questões econômicas, sociais e principalmente por perseguições (holocausto), enfatizando uma problemática de cunho internacional, criando desta forma um aparato universal de proteção e garantia aos direitos humanos. (SILVA; RODRIGUES, 2012).

Diante da amplitude do conceito relativo à migração, devemos delimitar o significado de refúgio. Portanto, para o $\operatorname{ACNUR}^{3}$ (2019, p. [1]), são considerados refugiados:

as pessoas que estão fora de seu país de origem e devido a fundado temores de perseguição relacionadas a questão de raça, religião, nacionalidade, pertencimento a um determinado grupo social ou opinião política, como também devido à grave e generalizada violação de direitos humanos e conflitos ${ }^{4}$.

Vê-se que a migração comum, que é tratada basicamente como transição de pessoas entre estados, países e regiões - particularmente por procura por melhores condições de vida, não envolvendo questões políticas - apresenta diferenças ante a questão do refugiado.

A instrumentalização da proteção do refugiado, está guarnecida na Declaração dos Direitos Humanos no artigo que trata sobre o direito de pedido de asilo em outros países a qualquer pessoa vítima de perseguição (artigo XIV). Muito embora haja esta proteção, de forma genérica, muitos doutrinadores se apegam às diferenças de asilo e refúgio. Porém de modo geral, concordam sobre a proteção do indivíduo perseguido. Contamos com vários desdobramentos em tratados internacionais para que esta proteção seja realmente levantada diante de qualquer violação, entre elas a Convenção de Genebra e seus protocolos, e mais tarde a Declaração de Viena de 1993, Declaração de Cartagena de 1984, além da proteção de cada Estado, dentro do seu limite interno. (JUBILUT, 2007).

Como norteador das garantias dos direitos e deveres, destacaremos primeiramente o ACNUR, que é um órgão das Nações Unidas que promove a assistência

\footnotetext{
3 Alto Comissariado das Nações Unidas para Refugiados.

4 Definição em harmonia com a Convenção de Genebra de 1951 e o Protocolo adicional de 1967.
} 
e proteção aos refugiados. Foi criado em 1950 para promoção do reassentamento dos refugiados europeus, que estavam sem destino e lar após a Segunda Guerra Mundial, e em 1995 expandiu o seu trabalho, então sem limites territoriais, alcançando todos os países ao redor do mundo. Importante órgão, que apoia e protege as pessoas que, por motivos de conflitos, perseguições e graves violações de direitos humanos, são forçadas a saírem do seu país, em busca de refúgio em outro local, para que não sofram torturas ou até morram em razão da raça, religião, nacionalidade, grupo social ou opiniões políticas. (ACNUR, 2019).

Pelo motivo de o refúgio ser tratado como política internacional, a ACNUR tem por objetivo viabilizar diretrizes e acessos para o cumprimento da proteção dos refugiados. Assim, além da sede, localizada em Genebra, estabelece ainda, escritórios regionais, que servem como facilitadores e aproximam as questões problemáticas da sua solução, sempre com características humanitárias, sem denotação política. (JUBILUT, 2007).

No Brasil, para além da atuação do ACNUR, contamos com a assistência do CONARE $^{5}$, criado em 1997 para implementar e organizar internamente as regras convencionadas na Convenção de Genebra de 1951, e também proceder com as autorizações, previstas em lei interna, à pessoa que entra no país para requerer a condição de refugiado. (ACNUR 2019).

No ordenamento brasileiro, além da própria Constituição Federal de 1988, viabilizada no seu art. $5^{\circ}$, também é observada a referida menção de proteção, resguardada em duas leis, com conteúdo mais direcionado à condição de refugiado no art. $5^{\circ}$ da Lei 9.474/1997. (Estatuto dos Refugiados de 1951):

Art. $5^{\circ} \mathrm{O}$ refugiado gozará de direitos e estará sujeito aos deveres dos estrangeiros no Brasil, ao disposto nesta Lei, na Convenção sobre o Estatuto dos Refugiados de 1951 e no Protocolo sobre o Estatuto dos Refugiados de 1967, cabendo-lhe a obrigação de acatar as leis, regulamentos e providências destinados à manutenção da ordem pública (BRASIL. Lei 9.474/1997).

E ainda na Lei 13.445/2017 (Lei de Migração), que viabiliza a questão migratória de forma abrangente, porém não menos importante na proteção do migrante geral, atende também o reconhecimento da condição do refugiado nos seus direitos e deveres, no art., $4^{\circ}$, in verbis:

Art. 4ํ Ao migrante é garantida no território nacional, em condição de igualdade com os nacionais, a inviolabilidade do direito à vida, à liberdade, à igualdade, à segurança e à propriedade, bem como são assegurados:

I - direitos e liberdades civis, sociais, culturais e econômicos;

II - direito à liberdade de circulação em território nacional;

III - direito à reunião familiar do migrante com seu cônjuge ou companheiro e seus filhos, familiares e dependentes;

5 Comitê Nacional para os Refugiados. 
IV - medidas de proteção a vítimas e testemunhas de crimes e de violações de direitos;

$\mathrm{V}$ - direito de transferir recursos decorrentes de sua renda e economias pessoais a outro país, observada a legislação aplicável;

VI - direito de reunião para fins pacíficos;

VII - direito de associação, inclusive sindical, para fins lícitos;

VIII - acesso a serviços públicos de saúde e de assistência social e à previdência social, nos termos da lei, sem discriminação em razão da nacionalidade e da condição migratória;

IX - amplo acesso à justiça e à assistência jurídica integral gratuita aos que comprovarem insuficiência de recursos;

X - direito à educação pública, vedada a discriminação em razão da nacionalidade e da condição migratória;

XI - garantia de cumprimento de obrigações legais e contratuais trabalhistas e de aplicação das normas de proteção ao trabalhador, sem discriminação em razão da nacionalidade e da condição migratória;

XII - isenção das taxas de que trata esta Lei, mediante declaração de hipossuficiência econômica, na forma de regulamento;

XIII - direito de acesso à informação e garantia de confidencialidade quanto aos dados pessoais do migrante, nos termos da Lei $n^{\circ} 12.527$, de 18 de novembro de 2011;

XIV - direito a abertura de conta bancária;

$\mathrm{XV}$ - direito de sair, de permanecer e de reingressar em território nacional, mesmo enquanto pendente pedido de autorização de residência, de prorrogação de estada ou de transformação de visto em autorização de residência; e

XVI - direito do imigrante de ser informado sobre as garantias que lhe são asseguradas para fins de regularização migratória.

$\S 1$ o Os direitos e as garantias previstos nesta Lei serão exercidos em observância ao disposto na Constituição Federal, independentemente da situação migratória, observado o disposto no $\S 4^{\circ}$ deste artigo, e não excluem outros decorrentes de tratado de que o Brasil seja parte. (BRASIL. Lei 13.445/2017).

O migrante que pretende solicitar o refúgio, geralmente por razões adversas, ingressa no país muitas vezes de forma ilegal, pois advém de situações, na maioria das vezes, de perseguição por questões políticas ou por estar fugindo de condições de guerra. Desta forma, cabe ao migrante realizar o seu pedido de refúgio, diante ao órgão competente, no caso brasileiro, a Polícia Federal, para regularização da sua estadia no país.

Esta solicitação será encaminhada ao CONARE, que, juntamente com a ACNUR e outros órgãos representativos do governo e da sociedade civil, fará a deliberação do reconhecimento do refúgio. Esta análise tem como base as condições dos países de origem, assim como, a condição individual motivadas no fundamento da lei, concedendo ou não a condição de refúgio ao solicitante, que gozará dos mesmos direitos que qualquer cidadão estrangeiro legalizado no país. (ACNUR, 2019).

Para Moreira (2014, p. 86), 
o vínculo jurídico-político do indivíduo ao Estado-nação, enquanto pertencimento a uma comunidade política, ainda se faz necessário, portanto, para o exercício e a concretização efetiva de direitos. Ao deixar seu país de origem e ingressar em outro país, para que a proteção estatal seja concedida e tal vínculo seja restabelecido, o indivíduo precisa ter reconhecido o estatuto de refugiado.

O relatório "Refúgios em números - $4^{\mathrm{a}}$ edição", realizado pelo CONARE, no ano de 2018, apresenta números cada vez mais crescentes de solicitações de reconhecimento e concessões de refúgio. O Brasil cumulou no ano de 2018, o total de 80.057 solicitações de reconhecimento da condição de refúgio, sendo 61.681 (representado por $77 \%$ do total) advindos da Venezuela. Apesar dos expressivos números de pedidos provenientes da Venezuela, o reconhecimento foi limitado ao número de 777 refugiados, considerando o primeiro lugar para a Síria, com 476 reconhecimentos; seguido da Palestina, com 52; e República Democrática do Congo, com 50 reconhecimentos, respectivamente. Para Venezuela houve elegibilidade somente para 5 reconhecimentos, número pequeno em comparação com as solicitações, pois muitos pedidos foram extintos ou arquivados (BRASIL. MINISTÉRIO DA JUSTIÇA E SEGURANÇA PÚBLICA, 2019).

Conforme destacam Crispim e Vincenzi (2018, p. 298):

Cumpre salientar, de início, que o Brasil entrou na rota da imigração mundial e vem recebendo solicitantes de refúgio da América Latina, da África e de alguns países da Ásia e da Síria. Destaca-se, ademais, a vinda de grande número de cidadãos da Síria na busca de refúgio desde o início da Guerra Civil em 2011 até a presente data. Além daqueles que oficialmente detém o status jurídico de refugiados, como os sírios, há também no Brasil grande contingente de solicitantes de refúgio, os quais, todavia, não têm perspectiva de verem-se agraciados com o Estatuto do Refugiado, por não possuem os requisitos legais para a permanência em território nacional como refugiados.

Vale ressaltar, que existem outras organizações que tratam do amparo ao refugiado, como a Cáritas e a Missão Paz, organizações estas que atuam em situações de vulnerabilidade e exclusão social.

A Cáritas é uma organização pertencente à igreja católica e funciona sem fins lucrativos em várias frentes na proteção dos mais vulneráveis, inclusive em extensão internacional. Sua origem foi determinada pelo auxílio de vítimas da Segunda Guerra Mundial e de um terremoto ocorrido no Japão, em 1948. Tem representatividade em várias frentes de apoio, porém, sua função principal é o atendimento de populações e suas grandes dificuldades, sendo um grande e fundamental suporte social.

Em seu domínio internacional, a Cáritas cumpre o seu relevante papel de observadora ligada ao Conselho Econômico e Social da ONU. No Brasil, desempenha as suas atividades junto à Conferência Nacional dos Bispos do Brasil (CNBB) e à Pastoral Social, que estão organizadas em várias arquidioceses espalhadas pelo território nacional, com destaque para as arquidioceses de São Paulo e Rio de Janeiro. (JUBILUT, 2007). 
A Cáritas Brasileira conta com diversas frentes e mobiliza mais de 15 mil agentes espalhados pelo Brasil, realizando diversos projetos - como economia popular solidária, convivência com biomas, programa de infância, adolescência e juventude, meio ambiente, gestão de riscos e emergências, migração e refúgio. Mas especificamente na área de migração e refúgio, a Cáritas São Paulo oferece serviços como assistência jurídica, assistência social, cursos e encaminhamento para trabalho e assistência psicológica. (CÁRITAS, 2019).

Outra entidade que tem a responsabilidade na defesa da população vulnerável, é a Missão Paz, entretanto, tem uma abordagem mais específica, por trabalhar no acolhimento de imigrantes e refugiados.

A Missão Paz é uma instituição filantrópica, vinculada à Igreja Católica (missionários Scalabrinianos), com localização na cidade de São Paulo, e tem como finalidade o acolhimento de imigrantes e refugiados. A instituição possui uma estrutura voltada para diversos tipos de serviços no amparo ao refugiado, dentre eles a Casa do Migrante, que abriga 110 indivíduos, onde são oferecidos alimentação, material de higiene pessoal, roupas, aulas de português, acompanhamento social e psicológico.

O Centro Pastoral e de Mediação dos Migrantes fornece serviços jurídicos, de documentação, de capacitação e saúde. Existe ainda um espaço de estudos migratórios (Centro de Estudos Migratórios), com biblioteca especializada em migração e, em especial, a publicação da revista Travessia. A entidade tem participação essencial na elaboração de medidas para melhoria da legislação e políticas migratórias locais, além de ter menção consultiva na ONU, por intermédio da Scalabrini International Migration Network. (MISSÃO PAZ, 2019).

Houve um avanço considerável na proteção dos refugiados e em temas que desdobram sobre direitos humanos, porém ainda carecem de atenção e medidas que visam a inclusão do refugiado na sociedade, sobretudo a superação do preconceito.

\section{ANÁLISE QUALITATIVA COTEJANDO OS ASPECTOS JURÍDI- COS E SOCIAIS A PARTIR DO OLHAR DO REFUGIADO}

A saída de uma pessoa do seu país acarreta sentimentos. Quando se trata de uma saída voluntária, o sentimento é de busca de novos anseios e horizontes, porém, quando tratamos de uma saída forçada, este sentimento pode ser visto como perda de pertencimento a qualquer atividade - retiram da pessoa um vínculo do ser, do estar, do ter, causando-lhe conflitos internos.

Este sentimento ainda pode ser intensificado, quando a saída é gerada por conflitos, perseguições e violações aos direitos humanos. O vínculo estabelecido até então com o país de origem, será modificado em virtude da aceitação da pessoa em outro país, porém os laços étnicos, culturais, deverão ser mantidos, a fim de resgatar sentimentos bons, de lembranças do passado.

A responsabilidade do país de acolhimento, não se restringe somente às regras impostas nas convenções e nas leis. O que foi vivido até então, é tão forte, que o país acolhedor tem por referência invocar o sentimento de pertencimento 
e dar guarida para tanto. Não se trata somente do aceitar o refugiado como cidadão, garantindo direitos e impondo deveres no novo país, como indicados nas leis 9.474/1997 e 13.445/2017, mas também como pessoa, uma vez que o sentimento de pertença está intimamente ligado ao seu social.

A intenção do presente trabalho visava argumentar a fragilidade e carência de políticas públicas em relação às pessoas em situação de refúgio na cidade de São Paulo, enfatizando o relacionamento de instituições públicas e organizações privadas no acolhimento destas pessoas.

Visava ainda: determinar por meio da pesquisa quantitativa como as condições dos refugiados eram respeitadas no que tange a ser reconhecido de forma legal no país, como ter um registro de identificação, acesso a serviços básicos de saúde e educação, condições documentais para ingresso ao mercado de trabalho. Quantificar a acessibilidade destes serviços aos refugiados ou pessoas em condição de refú gio ${ }^{6}$ e identificação do cumprimento dos direitos e garantias pertencentes aos refugiados.

A ideia de que a pesquisa seria uma volumosa fonte de informação, esbarrou em dificuldades, sendo a primeira delas a língua. Houve a tentativa de aplicação de questionário em locais com um número expressivo de refugiados, porém, sem condições de comunicação para entendimento das perguntas.

A segunda dificuldade, foi a desconfiança em responder o questionário e depois assinar o termo de consentimento para validação da pesquisa, atitude de fácil entendimento pela situação que os refugiados enfrentam.

Desta forma, a pesquisa, que na sua origem seria quantitativa, deu espaço a uma pesquisa qualitativa, com análise mais detalhada do enfrentamento pessoal de cada refugiado, com suas histórias e medos, que só quem passa por este tipo de situação tem a propriedade para falar.

A metodologia utilizada foi por instrumento de pesquisa exploratória, viabilizada por entrevista, com aplicação de questionário semiestruturado de perguntas abertas e fechadas.

Por razões já expostas anteriormente, a amostra consiste em duas pesquisas, sendo os dois entrevistados de origem africana (Angola e Mali), do sexo masculino, solteiros, com idade entre 35 e 40 anos. Ambos os entrevistados, em seu país de origem, viviam em condições favoráveis, trabalhavam, estudavam, todavia, participavam de atividades políticas e por perseguições, se viram obrigados a deixar o país.

A contraponto do que o objetivo principal do trabalho propunha, que era de analisar a carência de política pública no acesso a atendimento básico, entendemos que este ponto foi identificado como bem avaliado pelos entrevistados, concernente a serviços de estrutura básica, como atendimento em posto de saúde, emissão de Carteira de Trabalho, Cadastro de Pessoa Física, emissão de documentos em geral. Ambos os respondentes foram acolhidos pelos serviços básicos no Brasil.

6 Refugiado é aquela pessoa que já possui a qualificação/documentação como refugiado. Logo pessoas em condição de refúgio ainda estão com o processo de solicitação de refúgio sob análise. 
A Cáritas e a Missão Paz oferecem boa parte do apoio de direcionamento para os serviços públicos, e como a concentração das pessoas em refúgio é mais localizada na parte central da cidade, alguns órgãos já estão "habituados" aos atendimentos deste contingente, não havendo prejuízo de entendimento e falta de reconhecimento de documentos.

Para além das instituições de caráter social, temos algumas outras boas práticas advindas de instituições públicas, como universidades que admitem refugiados em cursos de graduação, disponibilizam amparo psicológico, programas de moradia, estágios remunerados, assim como grupos de trabalhos voltados para saúde, habitação e trabalho, organizados pela Secretaria de Justiça e Cidadania do Estado de São Paulo. (DEL GROSSI, 2014).

A aceitação de refugiados em universidades é considerada como uma boa prática local e temos o amparo em lei, preconizado no artigo 44 da Lei 9.474/97, que destaca:

Art. 44. O reconhecimento de certificados e diplomas, os requisitos para a obtenção da condição de residente e o ingresso em instituições acadêmicas de todos os níveis deverão ser facilitados, levando-se em consideração a situação desfavorável vivenciada pelos refugiados. (BRASIL. Lei 9.474/97).

Como se vê, é um dever do Estado - e não uma mera "bonificação" mencionada por várias instituições a título de ajuda.

Entretanto, a problemática está em âmbito privado, com a desconsideração dos documentos quando tratados de forma particular, seja em instituições bancárias, seja na hora da procura do emprego. Os entrevistados informaram que as instituições privadas acabam por negar o serviço ou recusar o candidato por não ter o entendimento do documento "protocolo de solicitação de refúgio" 7 , e mesmo por não ter o conhecimento de que os refugiados estão amparados pela legislação brasileira e não são pessoas em situação ilegal no país.

Muito embora o Ministério do Trabalho já tenha revisto o método de identificação no documento como referência a "estrangeiros com base na lei 9.474/97", em vez da menção da palavra "refugiados" (DEL GROSSI, 2014), ainda assim o não entendimento do que seja esta referência foi levantado por ambos os entrevistados.

Confirmando a dificuldade de acesso a instituições bancárias na abertura de conta, como relatado pelos entrevistados, o Ministério da Justiça e Segurança Pública, juntamente com o Banco Central e a ACNUR, lançou, em 07 de novembro de 2019, uma Cartilha de Informações Financeiras para Migrantes e Refugiados, informando sobre as práticas do sistema financeiro brasileiro. Dentre elas destacam-se as operações bancárias, aberturas de contas, empréstimos, dicas para não serem vítimas de golpes, reconhecimento de cédulas do Real. A distribuição da cartilha está sendo realizada em locais de grande fluxo de migrantes e refugiados

7 Protocolo de solicitação de refúgio é um documento oficial de identidade do solicitante de reconhecimento da condição de refugiado, e o autoriza a permanecer no Brasil até a decisão final de seu pedido. É válido em todo o território nacional. 
e em versões na língua portuguesa, espanhola, francesa e brevemente em árabe. (BRASIL. MINISTÉRIO DA JUSTIÇA E SEGURANÇA PÚBLICA, 2019).

Contudo, a situação de maior relevância, não tem limites em questões legais, estas deparam-se com as questões sociais. O sofrimento maior não é a falta do documento que lhe permite ser cidadão totalmente identificado nos parâmetros legais, o sofrimento consiste em não ter o reconhecimento como ser igual, obstante a todas as diferenças, raça, língua, cultura, não há o reconhecimento do ser humano.

Podemos associar este estranhamento social ao aspecto abordado por Georg Simmel (1984), que enfatiza a dinâmica do estrangeiro nessa busca constante no seu reconhecimento no meio social, associado com transformações sociais, culturais e econômicas (apud TEDESCO, 2007).

A falta de interação social trazida por Simmel (2004), dentre as suas análises, indica o sujeito como "estrangeiro", e que este pertence a um lugar e ao mesmo tempo não pertence, de modo que não abriu mão da sua liberdade de mobilidade, mas está atrelado a um contexto social determinado, e por ser diferente do enquadramento local, acaba por ser caracterizado o estranhamento ao grupo.

Ainda seguindo o raciocínio de Simmel (1999), abordado por Oliveira (2014, p. 86), e destacamos que "a figura do estrangeiro é inspiradora e socialmente rica. Ela mantém o grupo original em permanente processo de alteridade, indicando nesse movimento quão fugaz é a noção de identidade social".

Quando questionados sobre as dificuldades encontradas para inserção no país, os entrevistados foram enfáticos, relatando a discriminação e xenofobia. Ambos enfrentaram, em algum momento, preconceito pela condição de refúgio, raça ou condição social.

Bauman (2016) em uma determinação ampla, porém não justificável, identifica que a xenofobia enfrentada pelos "remanescentes" é fruto do medo dos estabelecidos, receio do enfrentamento do diferente, ansiedade dos indivíduos em não saber lidar com algo que não estamos acostumados e não saber como prever a reação. Esta imprevisibilidade causa distanciamento e a ignorância enfatiza esta sujeição a repelir tudo que é diferente.

Parte desta discriminação está vinculada à falta de interesse de conhecimento pelos pátrios, o que acaba gerando desencontro de informação, associando o refugiado a algo negativo, como criar a falsa ideia de que estes "estranhos" irão se apropriar de empregos e serviços disponibilizados aos pátrios. Dentre vários exemplos, temos o episódio de xenofobia que aconteceu em 2015 com o refugiado sírio que vendia salgados e doces no Rio de Janeiro e foi agredido verbalmente por um cidadão que portava pedaços de madeiras na mão. (CARTA CAPITAL, 2017).

Recentemente, um restaurante palestino, localizado em São Paulo, foi alvo de ataques por bombas e gás de pimenta (REVISTA FÓRUM, 2019). Estes ataques só enfatizam a falta de tolerância com o desconhecido, apesar de o Brasil ser considerado destaque no acolhimento amigável de refugiados.

E neste sentido Fonseca (2009, p. 280) aponta: 
[...] a violação mais que a exclusão é motor de mudança social, pois em uma cultura e cotidiano de perplexidade com ampla repercussão dada pelos meios de comunicação e informação de massa não há uma percepção imediata e comum de que duas situações são momentos de um mesmo eixo, que é a condição humana degradada e sempre ameaçada por novas degradações.

Outra característica que podemos apontar, é a vulnerabilidade econômica que é tida como consequência dos enfrentamentos no desenvolvimento em um país desconhecido.

Ambos os entrevistados, embora estejam empregados, expuseram um processo de busca por melhores condições de vida que esbarra em diversos pontos, como língua, desconhecimento de leis trabalhistas, falta de conhecimento das empresas na aceitação de documento de refugiado. Considerando o ambiente de trabalho, ainda enfrentam o desinteresse por parte dos colegas na aceitação da cultura, gastronomia, tornando-se assim, um ser isolado, fora do ambiente comum, totalmente alheio à integração. E por se tornarem alheios, se configuram vulneráveis, aceitando condições de trabalhos degradantes, sendo, por diversas vezes, explorados.

Muito embora consideramos o amparo jurídico uma das formas de solução de questões do cotidiano, estamos submetidos implicitamente a várias condições sociais, sendo que a legalidade e a estrutura social estão intimamente ligadas quando tratamos do indivíduo refugiado ou em condição de refúgio.

Por muitas vezes, as leis indicam taxativamente direitos e garantias, que socialmente são impossibilitadas, contudo não podemos somente levar em consideração o que está positivado, visto que outras questões influenciam na permanência estruturada deste indivíduo, como a economia, política e a própria cultura do Brasil no acolhimento.

E sobre este distanciamento da lei e da realidade social, Fonseca (2008, p. 291) destaca:

\begin{abstract}
A hipossuficiência, a carência material, a desvantagem econômica e social de certos indivíduos e grupos têm sido consideradas pelo ordenamento jurídico mediante a florescente (mas de certo modo infrutífera) legislação social. A exuberância das leis sociais e as hesitações formais do processo, cada vez mais autônomo, do direito material produzem um estranhamento e uma esterilidade decisória. O povo tem a viva impressão de que ganha, mas não leva.
\end{abstract}

Temos, na própria lei, princípios e garantias, como prescreve a Lei 13.445/2017, em seu artigo $3^{\circ}$ e alguns de seus incisos:

A política migratória brasileira rege-se pelos seguintes princípios e diretrizes:

II - repúdio e prevenção à xenofobia, ao racismo e a quaisquer formas de discriminação; 
IX - igualdade de tratamento e de oportunidade ao migrante e a seus familiares;

X - inclusão social, laboral e produtiva do migrante por meio de políticas públicas;

XI - acesso igualitário e livre do migrante a serviços, programas e benefícios sociais, bens públicos, educação, assistência jurídica integral pública, trabalho, moradia, serviço bancário e seguridade social;

XX - migração e desenvolvimento humano no local de origem, como direitos inalienáveis de todas as pessoas. (BRASIL. Lei 13.445/2017).

Diante do que foi analisado dentro da amostra disponível, ainda estamos longe de alcançar condições perfeitas para a pessoa do refugiado, muito embora a lei viabilize medidas obrigatórias e necessárias para inclusão social. A própria condição social na prática é que afasta o refugiado do seu direito e garantia.

\section{CONSIDERAÇÕES FINAIS}

As guerras sempre foram motivo para migração forçada em massa e a população se vê aflita à procura de novos horizontes e de uma nova vida longe de sofrimento e atrocidades trazidas pelo conflito.

E para dar uma especial proteção a essa população, especialmente após o grande acontecimento histórico da Segunda Guerra Mundial, surgiu a Organização das Nações Unidas (ONU).

A ONU enfatiza a garantia dos direitos humanos, trazendo uma ampla proteção no que diz respeito à dignidade da pessoa humana, independentemente de qualquer diferenciação entre elas, seja de raça, nacionalidade, sexo, etnia, religião, convicção política.

E diante desta fundamental proteção das pessoas de todos os países, foi proposto um alinhamento de caráter universal denominado Declaração Universal dos Direitos Humanos, uma espécie de recomendação com parâmetros mínimos de atuação para cada país signatário.

Como um guarda-chuva, esta distribuição é espalhada regionalmente e localmente, sempre obedecendo o mínimo estabelecido na declaração. E seguindo este mínimo imposto, temos também a proteção e garantia de grupos minoritários, entre eles, os refugiados.

Este grupo específico, denominado como refugiados - tem a sua fundamentação na saída forçada de seu país, devido a perseguições relacionadas à raça, religião, nacionalidade, grupo social, posição política - sofre violações aos direitos humanos.

No Brasil, temos o amparo a este grupo, notadamente em duas leis, Lei 9.474/97 e Lei 13.445/17, que estabelecem a garantia, proteção mínima e deveres em simetria com a normativas nacional e internacional.

A pesquisa proposta nos apresentou que, muito embora tenhamos uma base normatizada, o reconhecimento de grupos minoritários, mais especificamente o grupo de refugiados, enfrentam outras questões, que somente a lei em si, não é capaz de suprir. 
A questão social é fator preponderante para a integração na sociedade e podemos destacar como fatores essenciais: emprego, educação, saúde, entre outros, para tal inclusão.

E, por vezes, os refugiados são negligenciados, sem empregos, ou quando os tem são explorados; sem condições ideais de sobrevivência, expostos a situações adversas e fragilizados no meio social, carecendo de ajuda humanitária.

Concretiza-se um distanciamento entre a garantia normativa e a realidade prática, que seria minimizado se houvesse o reconhecimento do refugiado como parte da sociedade. Mas, para fazer parte da sociedade, ele precisa de emprego, educação, saúde. Estamos novamente diante do looping, que o afasta.

Para amenizar este distanciamento, podemos concluir que são necessárias algumas medidas para a integração de fato dos refugiados à sociedade local, como: ações de solidariedade com ampla divulgação, esclarecimento do conceito refugiado, capacitação da sociedade civil para reconhecimento de documentos e do próprio refugiado, desenvolvimento de campanhas de sensibilização, iniciativas que realmente incluam o refugiado como ser transformador do seu meio social.

Por fim, concluímos que a dignidade da pessoa humana, buscada pelo refugiado, só terá seu significado literalmente protegido quando obtiver o amparo legal e social.

\section{REFERENCIAS}

ANHCR-ACNUR Agência da ONU para Refugiados (Ed.). Protegendo refugiados no Brasil e no mundo. Disponível em: http:/ / caminhosdorefugio.com.br/wp-content/uploads/2014/11/Protegendo_refugiados_no_Brasil_e_no_mundo_2013.pdf. Acesso em: 08 abr. 2018.

BAUMAN, Zygmunt. Estranhos à nossa porta. Rio de Janeiro: Zahar, 2016.

BITTAR, EDUARDO C. B. (Org.). Direitos Humanos no Século XXI: Cenários de Tensão. Rio de Janeiro: Forense Universitária, 2008.

BOBBIO, Norberto. A Era dos Direitos. 3. ed. Rio de Janeiro: Elsevier, 2004.

BRASIL. Lei no 9.474, de 22 de julho de 1997. Disponível em: http:/ / www.planalto.gov. br/ccivil_03/leis/19474.htm. Acesso em: 28 ago. 2019.

BRASIL. Lei no 13.445, de 24 de maio de 2017.: Lei de Migração. Disponível em: http:/ / www. planalto.gov.br/ccivil_03/_ato2015-2018/2017/lei/113445.htm. Acesso em: 28 ago. 2019.

BRASIL. Min. da Justiça. Disponível em: https:/ / www.justica.gov.br/ news/ collective-nitf-content-1566502830.29. Acesso em: 28 ago. 2019.

BRASIL. Min. da Justiça. Disponível em: https:/ / www.justica.gov.br/seus-direitos/refugio/refugio-em-numeros. Acesso em: 28 de ago. 2019.

BRASIL. Min. da Justiça. Cartilha de informações financeiras para migrantes e refugiados. Disponível em: https://www.novo.justica.gov.br/news/cartilha-de-informacoes-finan- 
ceiras-para-migrantes-e-refugiados/cartilha-bc_versao-digital_portugues_pdf. Acesso em: 08 de nov. 2019.

CÁRITAS. Disponível em: http:/ / caritas.org.br/. Acesso em: 24 de nov. 2019.

CÁRITAS SÃOPAULO. Disponível em: https:/ / www.caritassp.org.br/centro-de-referencia-para-refugiados/. Acesso em: 24 de nov. 2019.

CARTA CAPITAL. Disponível em: https://www.cartacapital.com.br/politica/saia-do-meu-pais-agressao-a-refugiado-no-rio-expoe-a-xenofobia-no-brasil/. Acesso em: 29 de out. 2019.

CONARE. Refugiados e Conare. Disponível em: http://www.itamaraty.gov.br/pt-BR/ politica-externa/paz-e-seguranca-internacionais/153-refugiados-e-o-conare. Acesso em: 07 abr. 2018.

CRISPIM, Hilquias Moura; VINCENZI, Brunela Vieira de. REFUGIADOS \& ACESSO DEL GROSSI, Viviane Ceolin Dallasta. A atuação de defensoria pública da união e a implementação da política pública de assistência social aos refugiados no Brasil. In: RUGGERI RE, Aluisio Iunes Monti; REIS, Gustavo Augusto Soares dos; (ORG). São Paulo: Juspodivm, 2014. p. 449-489.

À JUSTIÇA: A SITUAÇÃO JURÍDICA DOS REFUGIADOS NO BRASIL: O DIREITO INTERNACIONAL DOS REFUGIADOS E O ORDENAMENTO JURÍDICO BRASILEIRO: UM PROBLEMA DE RECONHECIMENTO. In: ANNONI, Danielle, (ORG). Curitiba: Gedai, 2018. p. 292-311.

DIREITOS HUMANOS. In: HOUAISS, Antônio. Dicionário Houaiss da Língua Portuguesa. Disponível em: https:/ / www.dicio.com.br/direitos-humanos/. Acesso em: 05 out. 2019.

FONSECA, Paulo Henriques da. Direitos humanos dos pobres: entre a violação e a exclusão. In: BITTAR, Eduardo C. B. Direitos Humanos Século XXI: Cenários de Tensão. Rio de Janeiro: Editora Forense Universitária, 2008. p. 278-296.

GIL, Antonio Carlos. Métodos e técnicas de pesquisa social. 6. ed. São Paulo: Atlas, 2008.

JUBILUT, Liliana Lyra. O Direito Internacional dos Refugiados e sua Aplicação no Ordenamento Jurídico Brasileiro. São Paulo: Editora Método, 2007.

MAZZUOLI, Valério de Oliveira. Curso de Direito Internacional Público. 9. ed. São Paulo: Revista dos Tribunais, 2015.

MISSAO PAZ. Disponível em: http://www.missaonspaz.org/home. Acesso em: 24 de nov. 2019.

MOREIRA, Júlia Bertino. Refugiados no Brasil: reflexões acerca do processo de integração local. REMHU - Rev. Interdiscip. Mobil. Hum., Brasília, Ano XXII, n. 43, p. 85-98, jul./ dez. 2014. p. 86. 
ONU. Disponível em: https://nacoesunidas.org/direitoshumanos/. Acesso em: 23 de set. 2019.

OLIVEIRA, Márcio de. O Tema da Imigração na Sociologia Clássica. Dados - Revista de Ciências Sociais, Rio de Janeiro, v. 57, n. 01, p.73-100, mar. 2014.

ONU. Disponível em: https://nacoesunidas.org/wp-content/uploads/2018/10/DUDH. pdf. Acesso em: 23 de set. 2019.

ONU. UNHCR. ACNUR. Cartilha para refugiados no Brasil. Brasília: Agência ONU.

ONU. UNHCR. ACNUR. Guia para refugiados e solicitantes de refúgio em São Paulo. São Paulo: Agencia ONU.

PINA, Teresa. Direitos Humanos: O que está por fazer no século XXI. Lisboa: Temas e Debates - Círculo de Leitores, 2018.

PIOVESAN, Flávia. Direitos Humanos e o Direito Constitucional Internacional. 6. ed. São Paulo: Max Limonad, 2004.

PIOVESAN, Flávia. Direitos Humanos e Justiça Internacional: Um estudo comparativo dos sistemas regionais europeu, interamericano e africano. 2. ed. São Paulo: Saraiva, 2011.

RAMOS, André de Carvalho. Curso de Direitos Humanos. 4. ed. São Paulo: Saraiva, 2017. REVISTA FORUM. Disponível em: https://revistaforum.com.br/direitos/al-janiah-bar-de-refugiados-em-sp-sofre-ataque-fascista/. Acesso em: 29 de out. 2019.

SCHWINN, Simone Andrea; FREITAS, Priscila de. A PROTEÇÃO SOCIOJURÍDICA AOS REFUGIADOS NO BRASIL: DA LEGISLAÇÃO À POLÍTICA PÚBLICA. 2015. 20 f. Monografia (Especialização) - Curso de Direito, Universidade de Santa Cruz do Sul, Santa Cruz do Sul, 2015.

SILVA, César Augusto Silva da; RODRIGUES, Viviane Mozine. Refugiados: Os regimes internacionais de direitos humanos e a situação brasileira. In: SILVA, César Augusto S. da (Org.). Direitos Humanos e Refugiados. Dourados: Ufgd, 2012.

SIMMEL, Georg. Fidelidade e gratidão e outros textos. Lisboa, Relógio D’Água, 2004.

TEDESCO, João Carlos. Georg Simmel e as ambiguidades da modernidade. Ciências Sociais, Unisinos, Passo Fundo, v. 43, n. 1, p. 57-67, 2007.

TRINDADE, Antônio Augusto Cançado. Os Tribunais Internacionais Contemporâneos. Brasília: Funag, 2013. 


\section{APÊNDICE - QUESTIONÁRIO}

\section{QUESTIONÁRIO}

Nacionalidade:

Idioma de origem:

Cidade de origem (do país de origem):

Data de nascimento:

Gênero: ( ) masculino ( ) feminino ( ) outro

Estado civil: ( ) Solteiro ( ) Casado ( ) União Estável ( ) Divorciado ( )Viúvo Cor: ( ) Branca ( ) Preta ( )Amarela ( ) Parda ( ) Indígena

( ) Sem declaração

Data de ingresso ao Brasil:

Se este é o primeiro ingresso:

Por qual cidade / estado brasileiro ingressou:

Se veio acompanhado de familiares, se sim, quais?

Escolaridade: ( ) Ensino Fundamental ( ) Ensino Médio ( ) Ensino Superior

Profissão:

Inserção no mercado de trabalho no país de origem:

Inserção no mercado de trabalho brasileiro:

Serviços básicos oferecidos pelo Estado brasileiro aos quais já teve acesso:

( ) RNE ou equivalente (Polícia Federal)

( ) SUS (Saúde)

( ) Ensino público (Educação)

( ) $\mathrm{CPF}$ (Receita Federal)

( ) CTPS (MTE)

Roteiro de questões abertas:

Motivações para migrar para o Brasil?

1. Expectativas quanto à permanência no país?

2. Em que medida essas expectativas foram satisfeitas - ou não?

3. Quais as dificuldades encontradas para inserção no país?

4. É/foi amparado por alguma instituição no Brasil?

5. Experiências no processo de inserção que merecem, para o entrevistado, destaque. 


\section{ANEXO - APROVAÇÃO DO COMITÊ DE ÉTICA EM PESQUISA}

\section{UNIVERSIDADE METODISTA \\ DE SÃO PAULO - UMESP}

\section{PARECER CONSUBSTANCIADO DO CEP}

\section{DADO \& DO PROJETO DE PEBQUIBA}

Titulo da Posquilea: A INOEFENSABILIDADC $D$ REFUGLADO NO ASPECTO LEGN E SOCIN Pocgultsdor: BARBARA MOURAO SACHETT

Ares Tematies:

Voreso: 1

CAAE: 95772718.5 .0000 .5506

Institulipso Proponente: Uriverskidede Metodista de SSo Pajo - UMESP

Patroeinador Prinolpal: Finenciamento Propio

DADO 8 DO PARECER

Numero do Parecer: 2.880 .937

Aprecentagso do Projeto:

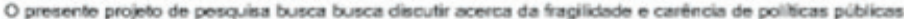

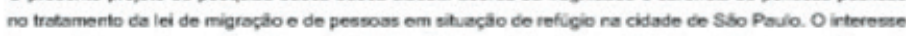

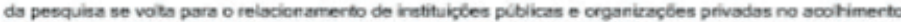
destas pessoas em situaçbo de retugio. Tem a finalidade de esciarecer a ajuda cispendica para um recomeço e qual a efetividade deste amparo a um ser humano wilneravel per motivos aheics a sua vontade. Para tanto, tara use de entrevista semiestnuturace por meio de questicnario.

\section{Objetivo da Pesquis:}

O estudo tem como objetivo principel ansisar o amparo aos micrantes na condiçbo de refígio na cidade co Sto Paulo. Apreserta como objutiven espeolficos:

a) everiguar a efetividade na bi de migracão na ertrada do migrartes e es direitce pertinentes na situacle de retigio:

b) cescobrir como as entidades publicas e erganizacles privadas acoithem o migrarte na condiça de nengio:

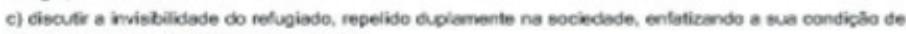
ser humano antericr a situecto de refugie. 


\section{UNIVERSIDADE METODISTA DE SÃO PAULO - UMESP}

Cretreub as nere a amert

\section{Avallagao doc Riseoc o Bentholoc:}

A pescuisa indica como posaiveis benelicios apontar a eleciviade da atuaçlo dos

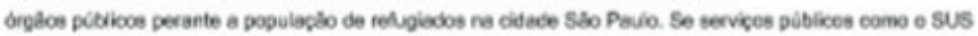
e escolas poblicas estlo cumprinco o papel na amcetra apresertada.

Como riscos, a pescuise apresenta a possivel recordepdo de mementos delcados de pastado que o obrigaram a deixar o pais de origem e e propilo enfrentamento em um pais com lingua estruturas desconhecidas. Destaca ainda eve, o entrevistaco tera live esceihe em continuar a entrevista, caso as recordaches e atual shuacdo the tragam desconforto em resconder o euestionario.

\section{Comentarios o Conclderagoes cobre secquics:}

A pescuisa dencta interesse cientifico e social, apresentado cuidade e abençbe dionte dos perticipantes. fundementando sua reievbria ne conário da refexto juridica.

\section{Conclderapoes sobre os Termos de aprecentapaso obriestoris:}

Documertaça apresentado conforme exigèncias eticas. Declaraçbo da aluna pesquisadora, bem como da orientadora e da Insthuçto Ce Participante atendem as exigetecias.

\section{Conolusoes ou Pondinoles o Liste de inadequagoes:}

Apbs leitura e andise do projeto e exame criterioso de todos os itens eue ccmobem os documertos do Protocolo de Peseuisa, incluindo on iters presentes no Roteive de Checagem pera o pareceriata e o Termo de Consentimento Livre e Csclarecido nads fei censtatado no processo que fra ca princlpios e ncrmas da etica em peseusa.

\section{Conciderapoes Finals a ortiterio do CEP:}

O CEP.UMESP considera o projoto de pesquisa APROVADO, lembrando que a condicho de aprovaço da posqualsa proprismente cita exige o que segue:

- Que sejom encaminhados a CEP.UMCSP relatónos anuais sobre o andamerto da pesquiea (parcisis e fnais):

- Que sejam notficados ao CEP.UMCSP eventos adversos qu lenham ccorrico no curvo da pesquina eque sejam sionificatives do pento de vista

- Que sejem notficadas evertuais emendas e modificapbes no pretcceb de pesquina.

Este parecer fol alaborado baceado nos dooumentes abalxo ralablonadoc:

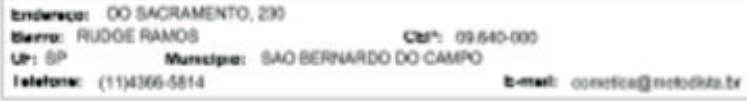

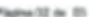




\section{UNIVERSIDADE METODISTA DE SÃO PAULO - UMESP}

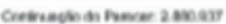

\begin{tabular}{|c|c|c|c|c|}
\hline Too Dooumento & Arquvo & Potagem & ACAOE & 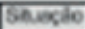 \\
\hline 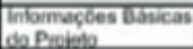 & 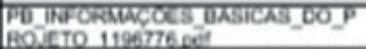 & $\begin{array}{c}\text { T30iा/2018 } \\
16.46 .59\end{array}$ & & Acoto \\
\hline $\begin{array}{l}\text { TCLC / Temos Ce } \\
\text { Asoentimento / } \\
\text { Justricativa de } \\
\text { Ausedecia. }\end{array}$ & $\begin{array}{l}\text { Trawo of CONSCNTMENTO_LIVR } \\
\text { CE_ESCLARECIOO pol }\end{array}$ & $\begin{array}{c}1300 / 2018 \\
16: 44: 40\end{array}$ & 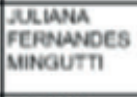 & Acoto \\
\hline Fotha de Roeto & Fota_do_roetio pdr & $\begin{array}{c}70082018 \\
14.08 .00\end{array}$ & 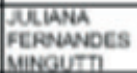 & Aceto \\
\hline $\begin{array}{l}\text { Propho Detaihado I } \\
\text { Brochura } \\
\text { inseatigadod }\end{array}$ & 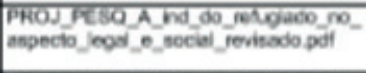 & 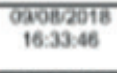 & 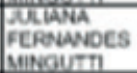 & Aceto \\
\hline 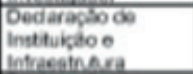 & $\begin{array}{l}\text { Dociaracao_instikcas_copartcipantes. } \\
\text { Pof }\end{array}$ & $\begin{array}{l}9201 / 2018 \\
15: 56.14\end{array}$ & 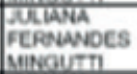 & Aceto \\
\hline $\begin{array}{l}\text { Oedaracso do } \\
\text { Peseuisodores }\end{array}$ & Doclaracao pesquinadores pol & 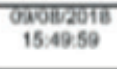 & 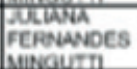 & Aceto \\
\hline
\end{tabular}

Sttuagse do Pareese:

Aprovado

Nosecelta Apreolapso da CONEP:

Nbo

SAO DERNARDO DO CAMPO, 06 Ge Setembre de 2018

Ascinado por:

Dario Paulo Earrera Avers

(Coerdensdor)

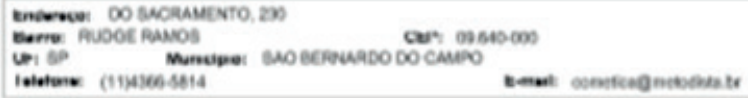

